\title{
O princípio da não-cumulatividade no IPI: a adoção do sistema constitucional da compensação do crédito tributário
}

Patricia Audibert Nader ${ }^{1}$ Patricia Martins Valente ${ }^{2}$

\section{Resumo}

\begin{abstract}
Este artigo tem por escopo a realização de uma sucinta análise da regra matriz do IPI - Imposto sobre Produtos Industrializados, analisando rapidamente a hipótese tributária (critério material, temporal e espacial) e a relação jurídica tributária (critério pessoal - sujeito ativo e passivo - e quantitativo - base de cálculo e alíquota). Outrossim, examina o princípio da não-cumulatividade, a sua positivação e os possível critérios a serem adotados para se garantir a efetiva aplicação desse princípio constitucional. Finalmente, ingressa no estudo da compensação do crédito tributário, mecanismo que garante maior eficácia ao princípio da nãocumulatividade.
\end{abstract}

Palavras-Chave: IPI; Princípio da não-cumulatividade; Compensação do crédito tributário.

\section{Introdução}

A regra matriz de incidência foi formulada pelo professor Paulo de Barros Carvalho, com o intuito de identificar a natureza jurídica, o sentido e o alcance das diferentes espécies tributárias.

Utilizando o direito positivo referente ao IPI - Imposto sobre Produtos Industrializados obtém-se os elementos que compõe a regra matriz: hipótese tributária (critério material, espacial e temporal) e relação jurídica tributária (critério pessoal e quantitativo).

Somente após a edificação da regra matriz do IPI é que se pode observar outros aspectos deste tributo. No caso deste artigo, será analisado o princípio da nãocumulatividade e a compensação do crédito tributário.

O princípio da não-cumulatividade consiste na dedução do valor do imposto correspondente à saída dos produtos do estabelecimento industrial com o valor do imposto que incidiu nas operações anteriores sobre os respectivos insumos.

$\begin{array}{ll}1 & \text { Estudante de Direito da Universidade Estadual de Londrina. } \\ 2 & \text { Estudante de Direito da Universidade Estadual de Londrina. }\end{array}$ 
Sendo assim, afere-se que a compensação é uma técnica que visa a concretização efetiva do princípio da não-cumulatividade.

\section{Regra matriz}

\subsection{Hipótese tributária}

\subsubsection{Critério material}

O art. 46 do Código Tributário Nacional, discorre in verbis:

Art. 46. O imposto, de competência da União, sobre produtos industrializados tem como fato gerador:

I - o seu desembaraço aduaneiro, quando de procedência estrangeira;

II - a sua saída dos estabelecimentos a que se refere o parágrafo único do artigo 51;

III - a sua arrematação, quando apreendido ou abandonado e levado a leilão.

Parágrafo único. Para os efeitos deste imposto, considera-se industrializado o produto que tenha sido submetido a qualquer operação que lhe modifique a natureza ou a finalidade, ou o aperfeiçoe para o consumo.

Desembaraço aduaneiro é a entrada formal, jurídica do produto no território nacional. O desembaraço é fato gerador do IPI, do imposto de importação e do ICM.

A bitributação (ICM e imposto de importação), nesse caso, está prevista na Constituição, sendo, portanto, constitucional.

O bis in idem (IPI e imposto de importação) não está expressamente proibido pela Constituição, portanto, não é considerado inconstitucional.

A arrematação dos produtos levados a leilão não se refere à industrialização, porque é uma compra. Outrossim, esse fato gerador se encontra revogado (CARVALHO, 2005, p. 351).

O fato gerador é a saída do estabelecimento industrial ou equiparado a industrial por conta da lei (v.g.: importador), portanto, a simples industrialização do produto não é fato gerador. Além disso, deve-se ressaltar que para se configurar o fato gerador, deve ocorrer a transferência da posse ou da propriedade dos produtos. 


\subsubsection{Critério temporal}

Os fatos geradores do IPI, assim como do ICM, do imposto de Importação e de Exportação, são instantâneos ou simples, i.e., é aquele que ocorre em um momento certo, temporalmente identificado.

Desta forma, o critério temporal do IPI é composto dos seguintes momentos:

- Desembaraço aduaneiro;

- Saída do produto industrializado do estabelecimento produtor; e

- Arrematação em leilão da mercadoria apreendida ou abandonada.

\subsubsection{Critério espacial}

Por ser um tributo federal, incidirá em qualquer local do território nacional em que o critério material ocorra.

\subsection{Relação jurídica tributária}

\subsubsection{Critério pessoal}

A presença de dois sujeitos (o ativo e o passivo) é exigida para se configurar a relação obrigacional.

O sujeito ativo da relação tributária do IPI é a União, conforme pode ser observado pelo art. 153, IV da Constituição Federal.

Os sujeitos passivos (contribuintes) são estabelecidos pelo art. 51 do CTN, que discorre in verbis:

Art. 51. Contribuinte do imposto é:

I - o importador ou quem a lei a ele equiparar;

II - o industrial ou quem a lei a ele equiparar;

III - o comerciante de produtos sujeitos ao imposto, que os forneça aos contribuintes definidos no inciso anterior;

IV - o arrematante de produtos apreendidos ou abandonados, levados a leilão.

Parágrafo único. Para os efeitos deste imposto, considera-se contribuinte autônomo qualquer estabelecimento de importador, industrial, comerciante ou arrematante. 
O IPI é um imposto indireto e, portanto, gera repercussão econômica, ou seja, o custo é repassado para o próximo na cadeia (surgindo as figuras do contribuinte de fato e de direito).

\subsubsection{Critério quantitativo}

O critério quantitativo possui o escopo de determinar o valor da prestação devida pelo sujeito passivo.

\subsubsection{Base de cálculo}

De acordo com Aires Barreto (1998, p. 74), base de cálculo é a perspectiva mensurável da hipótese.

As bases de cálculo do IPI são:

- O preço que serviu de base de cálculo para os tributos aduaneiros, acrescido do montante do imposto sobre a importação, das taxas exigidas para a entrada do produto no país e dos encargos cambiais efetivamente pagos pelo importador; ou

- O valor da operação de saída da mercadoria do estabelecimento industrial ou, não havendo, o preço corrente da mercadoria no mercado atacadista da praça do remetente; ou

- O preço da arrematação em leilão de produtos apreendidos ou abandonados.

\subsubsection{Alíquota}

As alíquotas do IPI são seletivas em função da essencialidade do produto e estão previstas na TIPI - Tabela de Incidência do IPI (Decreto no 4.544/02).

André de Souza Dantas Elali (2005, p. 76) esclarece:

Em face de ser o IPI Em face de ser o IPI excepcionado em relação a alguns princípios constitucionais, as suas alíquotas não precisam ser modificadas por leis em sentido formal, bastando manifestação do Chefe do Executivo Federal, in casu o Presidente da República, por meio de Decretos, desde que atendendo às limitações constitucionais (CF/88, art. 153). E isto porque a própria norma constitucional admite, havendo sido tal autorização regulamentada pelo Dec.-lei 1.199/71. 


\title{
3 Princípio da não-cumulatividade
}

Ao instituir o princípio da não-cumulatividade, o constituinte visou favorecer o contribuinte de direito, atenuando os custos de produção, o que, conseqüentemente, reflete no contribuinte de fato, com a atribuição de preços menos onerados pela carga tributária (BOTTALLO, 2002, p. 45).

[...] O IPI é tributo de natureza indireta, uma vez que o contribuinte de fato é o consumidor final da mercadoria objeto da operação, visto que a empresa, que repassa no preço da mercadoria o imposto devido, recolhendo posteriormente aos cofres públicos o imposto já pago pelo consumidor final, e, em conseqüência, não assume a respectiva carga tributária. Opera-se, assim, no caso do IPI, a substituição legal no cumprimento da obrigação, do contribuinte de fato pelo contribuinte de direito, inadmitindo-se a repetição do indébito e a compensação do referido tributo, sem a exigência da prova da repercussão [...]. (STJ - Resp. 411.478 - PR 1a T. - Rel. Luiz Fux - DJU 28.10.2002)

Hugo de Brito Machado (2004, p. 158) obtempera:

\begin{abstract}
A expressão não-cumulatividade do tributo pode ter vários significados. Um deles seria o de que sobre o mesmo fato não poderiam incidir vários tributos. Outro seria o de que um tributo sobre fato integrante de uma sucessão de fatos da mesma natureza não pode incidir sobre cada um desses fatos de forma autônoma, acumulando-se cada incidência com as incidências anteriores. É com este segundo significado que a expressão tem sido geralmente empregada em nosso sistema tributário
\end{abstract}

Outrossim, tal doutrinador observa que a não-cumulatividade pode ser vista como técnica ou princípio. Assim, quando exposta de forma genérica é um princípio, i.e., quando não se estabelece categoricamente o modo pelo qual a não-cumulatividade deve ser efetivada, tem-se um princípio. Por outro lado, quando se determina o modo pelo qual o princípio deve ser realizado, executado ou efetivado; tem-se a técnica da nãocumulatividade.

O princípio da não-cumulatividade, de acordo com Eduardo Domingos Bottallo (2002, p. 45), possui as seguintes qualidades:

é neutro, devendo ser indiferente tanto na competitividade e concorrência quanto na formação de preços no mercado;

onera o consumo e nunca a produção ou o comércio, adaptando-se às necessidades de mercado; 
oferece maiores vantagens ao Fisco, pois sendo plurifásico, permite antecipar o imposto que seria devido apenas no consumo (vantagens financeiras), e coloca ademais todos os agentes econômicos das diversificadas etapas de industrialização e circulação como responsáveis pela arrecadação (vantagens contra o risco de insolvência).

\section{O IPI é um tributo plurifásico, ou seja, é resultado de um ciclo operacional e, por} isso, justifica-se a aplicação do princípio da não-cumulatividade.

Além do IPI, devem respeitar o princípio da não-cumulatividade os tributos: ICM, Contribuições previdenciárias residuais da União, Impostos residuais da União e Contribuições do art. 195 da Constituição Federal ${ }^{3}$.

${ }^{3}$ Art. 195. A seguridade social será financiada por toda a sociedade, de forma direta e indireta, nos termos da lei, mediante recursos provenientes dos orçamentos da União, dos Estados, do Distrito Federal e dos Municípios, e das seguintes contribuições sociais:

I - do empregador, da empresa e da entidade a ela equiparada na forma da lei, incidentes sobre:

a) a folha de salários e demais rendimentos do trabalho pagos ou creditados, a qualquer título, à pessoa física que lhe preste serviço, mesmo sem vínculo empregatício;

b) a receita ou o faturamento;

c) o lucro;

II - do trabalhador e dos demais segurados da previdência social, não incidindo contribuição sobre aposentadoria e pensão concedidas pelo regime geral de previdência social de que trata o art. 201;

III - sobre a receita de concursos de prognósticos.

IV - do importador de bens ou serviços do exterior, ou de quem a lei a ele equiparar.

$\S 1$ 으 - As receitas dos Estados, do Distrito Federal e dos Municípios destinadas à seguridade social constarão dos respectivos orçamentos, não integrando o orçamento da União.

§ 2 o - A proposta de orçamento da seguridade social será elaborada de forma integrada pelos órgãos responsáveis pela saúde, previdência social e assistência social, tendo em vista as metas e prioridades estabelecidas na lei de diretrizes orçamentárias, assegurada a cada área a gestão de seus recursos.

§ 3o - A pessoa jurídica em débito com o sistema da seguridade social, como estabelecido em lei, não poderá contratar com o Poder Público nem dele receber benefícios ou incentivos fiscais ou creditícios.

§ 4으- A lei poderá instituir outras fontes destinadas a garantir a manutenção ou expansão da seguridade social, obedecido o disposto no art. 154, I.

$\S 5$ o - Nenhum benefício ou serviço da seguridade social poderá ser criado, majorado ou estendido sem a correspondente fonte de custeio total.

§ 60 - As contribuições sociais de que trata este artigo só poderão ser exigidas após decorridos noventa dias da data da publicação da lei que as houver instituído ou modificado, não se lhes aplicando o disposto no art. 150, III, "b".

$\S 7$ ㅇ - São isentas de contribuição para a seguridade social as entidades beneficentes de assistência social que atendam às exigências estabelecidas em lei.

$\S 8$ o 0 produtor, o parceiro, o meeiro e o arrendatário rurais e o pescador artesanal, bem como os respectivos cônjuges, que exerçam suas atividades em regime de economia familiar, sem empregados permanentes, contribuirão para a seguridade social mediante a aplicação de uma alíquota sobre o resultado da comercialização da produção e farão jus aos benefícios nos termos da lei.

$\S 9$ ㅇ As contribuições sociais previstas no inciso I do caput deste artigo poderão ter alíquotas ou bases de cálculo diferenciadas, em razão da atividade econômica, da utilização intensiva de mão-deobra, do porte da empresa ou da condição estrutural do mercado de trabalho.

$\S 10$. A lei definirá os critérios de transferência de recursos para o sistema único de saúde e ações de assistência social da União para os Estados, o Distrito Federal e os Municípios, e dos Estados para os Municípios, observada a respectiva contrapartida de recursos. 


\section{Critérios adotados para a incidência do princípio da não-cumulatividade}

A adoção de um sistema não em cascata foi previsto pela Constituição Federal apenas em relação a dois impostos: o IPI e o ICM.

Para tanto, pode-se utilizar dois critérios: "base sobre base" ou "imposto sobre imposto".

O critério "base sobre base", também denominado de "basis on basis", considera que o valor acrescido é a diferença entre o montante das vendas e o das aquisições no mesmo período, ou seja, o valor agregado em cada operação.

Enquanto que no método "imposto sobre imposto" o valor acrescido é definido como sendo a diferença entre imposto a pagar e o imposto já pago pelos bens adquiridos no mesmo período (COSTA, 1978, p. 26-27).

Aparentemente, esses métodos se equivalem. No entanto, tal conclusão não é correta, pois isso só ocorre se as alíquotas de cada operação forem uniformes. Destarte, pode-se concluir que no sistema "imposto sobre imposto" a alíquota das fases anteriores ou a isenção do produto influenciam as fases precedentes.

Observa-se essa diferença patente através de exemplos:

O contribuinte B compra de A, por 100, determinado produto que revende por 200 . Eis as hipóteses:

Alíquota uniforme de $10 \%$

Cálculo base sobre base: $(200-100) \times 10 \%=10$

Cálculo imposto sobre imposto: $(200 \times 10 \%)-(100 \times 10 \%)=10$

Alíquota de $5 \%$ nas vendas de $A$ e de $10 \%$ nas vendas de $B$

Cálculo base sobre base: $(200-100) \times 10 \%=10$

Cálculo imposto sobre imposto: $(200 \times 10 \%)-(100 \times 5 \%)=15$

Alíquota de $15 \%$ nas vendas de $A$ e de $10 \%$ nas vendas de $B$

Cálculo base sobre base: $(200-100) \times 10 \%=10$

Cálculo imposto sobre imposto: $(200 \times 10 \%)-(100 \times 15 \%)=5$ (PHILIPPE, 1978, p. 26-27).

A "Teoria do Valor Acrescido" assevera que a alíquota deve incidir sobre valor acrescido ao bem. Alguns doutrinadores defendem que está Teoria foi a adotada no Brasil.

$\S 11$. É vedada a concessão de remissão ou anistia das contribuições sociais de que tratam os incisos I, a, e II deste artigo, para débitos em montante superior ao fixado em lei complementar.

$\S 12$. A lei definirá os setores de atividade econômica para os quais as contribuições incidentes na forma dos incisos I, b; e IV do caput, serão não-cumulativas.

$\S 13$. Aplica-se o disposto no $\S 12$ inclusive na hipótese de substituição gradual, total ou parcial, da contribuição incidente na forma do inciso l, a, pela incidente sobre a receita ou o faturamento. 
No entanto, o plenário do III Simpósio Nacional de Direito Tributário do Centro de Estudos de Extensão Universitária conclui por unanimidade que o princípio constitucional da nãocumulatividade consiste em abater do imposto devido o montante exigível nas operações anteriores, sem qualquer consideração à existência de valor acrescido.

Assim, infere-se que a Constituição brasileira adotou o sistema de dedução "imposto sobre imposto", no que se refere ao IPI.

\section{Positivação do princípio da não-cumulatividade no Brasil}

A Constituição Federal, em seu art. 153, §3ำ, II, prevê o princípio da nãocumulatividade para o IPI:

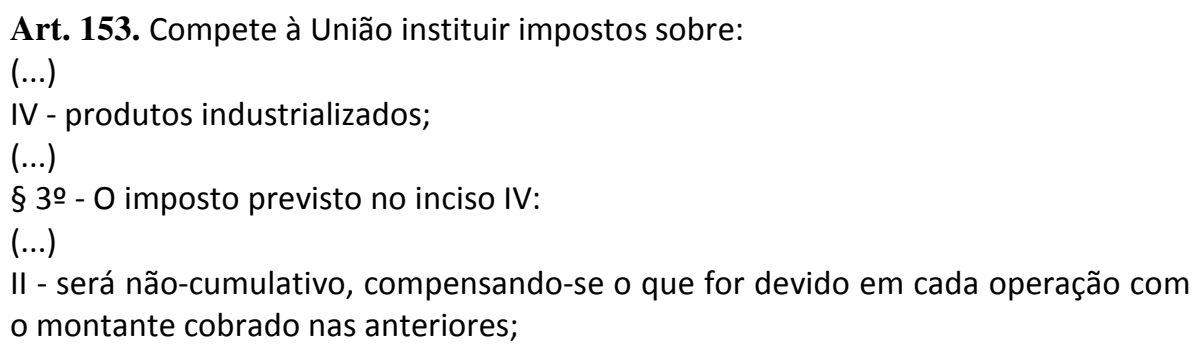

A expressão "compensando-se o que for devido em cada operação" confere ao contribuinte um direito subjetivo de abatimento, com o escopo de frear a ação do Poder Público (BOTTALLO, 2002, p. 44).

Através da interpretação literal desse dispositivo, afere-se que o princípio da nãocumulatividade no IPI deve ser aplicado por produto. No entanto, se assim fosse, a aplicação desse princípio seria inviável.

Desta forma, prevalece o disposto o art. 49 do Código Tributário Nacional, que estabelece o princípio da não-cumulatividade por período:

Art. 49. O imposto é não-cumulativo, dispondo a lei de forma que o montante devido resulte da diferença a maior, em determinado período, entre o imposto referente aos produtos saídos do estabelecimento e o pago relativamente aos produtos nele entrados.

Parágrafo único. O saldo verificado, em determinado período, em favor do contribuinte transfere-se para o período ou períodos seguintes.

O Regulamento do IPI (Decreto no 2.637/98), por sua vez, em seus art. 146 e 147, I discorrem ipsis litteris: 
Art. 146. A não-cumulatividade do imposto é efetivada pelo sistema de crédito, atribuído ao contribuinte, do imposto relativo a produtos entrados no seu estabelecimento, para ser abatido do que for devido pelos produtos dele saídos, num mesmo período, conforme estabelecido neste Capítulo (Lei no 5.172, de 1966, art. 49).

$\S 1$ 응 0 direito ao crédito é também atribuído para anular o débito do imposto referente a produtos saídos do estabelecimento e a este devolvidos ou retornados. $\S 2$ ㅇ Regem-se, também, pelo sistema de crédito os valores escriturados a título de incentivo, bem assim os resultantes das situações indicadas no art. 163.

Art. 147. Os estabelecimentos industriais, e os que lhes são equiparados, poderão creditar-se (Lei no 4.502, de 1964, art. 25):

I - do imposto relativo a matérias-primas, produtos intermediários e material de embalagem, adquiridos para emprego na industrialização de produtos tributados, incluindo-se, entre as matérias-primas e produtos intermediários, aqueles que, embora não se integrando ao novo produto, forem consumidos no processo de industrialização, salvo se compreendidos entre os bens do ativo permanente;

Portanto, verifica-se que o crédito do IPI relativo aos insumos só é admitido se resultar saída tributada de sua industrialização, exceto quando houver lei que conceda benefícios ou incentivos fiscais.

No entanto, Ives Gandra Martins (1999, p. 9-10) conclui que, no Brasil,

a não-cumulatividade se dá de imposto sobre imposto, mas correspondendo à totalidade de operações de entradas para a totalidade das operações de saídas em um período, mesmo que a mercadoria ou a matéria-prima que entrou incidida não tenha saído ou sido utilizada naquele período. Denomina-se "técnica periódica", pois periodicamente abate-se o imposto incidente sobre as operações anteriores daquele que incidirá sobre as novas operações e, desta conta de crédito e débito, surge o tributo a pagar ou a escriturar criando-se um crédito a ser deduzido do futuro imposto a recolher, se naquele período o tributo a recolher foi inferior ao incidido anteriormente.

\section{Compensação do crédito tributário}

A compensação é o mecanismo de maior eficácia do princípio da nãocumulatividade e pode ser definida como a dedução ou o abatimento dos montantes cobrados de IPI nas operações anteriores.

O contribuinte possui o direito público e subjetivo de realizar a compensação, que, por sua vez, está prevista na Constituição como uma norma de eficácia plena e aplicabilidade imediata.

A Constituição confere ao contribuinte o direito de abater o valor devido por outros contribuintes que lhe forneceram mercadorias do montante de IPI a pagar, instaurando-se uma relação de créditos e débitos. 
Outrossim, o legislador pode conceder ao contribuinte o direito de créditos não resultantes da entrada de mercadorias em seu estabelecimento. Exemplificando, têm-se as hipóteses previstas no Decreto 2.637/98, em seus art. 157 e 158 (créditos como incentivo à SUDENE e à SUDAM), art. 164 (crédito presumido em estímulo a produtores de açúcares em determinadas regiões do país) e art. 165 (crédito com ressarcimento de contribuições incidentes sobre o faturamento de empresas que promovem operações de exportação).

A compensação refere-se às operações realizadas em um determinado período de tempo. Sendo assim, se nesse período os débitos forem superiores aos créditos, o contribuinte deverá recolher imposto. Por outro lado, se nesse período os créditos forem superiores aos débitos, os créditos remanescentes são transferidos para o próximo período de apuração.

Assim, estabelece o art. 11 da Lei 9.779/99:

Art. 11. O saldo credor do Imposto sobre Produtos Industrializados - IPI, acumulado em cada trimestre-calendário, decorrente de aquisição de matériaprima, produto intermediário e material de embalagem, aplicados na industrialização, inclusive produto isento ou tributado à alíquota zero, que o contribuinte não puder compensar com o IPI devido na saída de outros produtos, poderá ser utilizado de conformidade com o disposto nos arts. 73 e 74 da Lei 9.430, de 1996, observadas as normas expedidas pela Secretaria da Receita Federal - SRF, do Ministério da Fazenda.

Os art. 73 e 74 da Lei 9.430/96 regram, sucintamente, que a compensação deverá ser efetuada através de um procedimento interno na Secretaria da Receita Federal; que deverá ser realizada mediante entrega de declaração do sujeito passivo, que deve dispor sobre os créditos a serem utilizados e os débitos a serem compensados; e regram ainda que a compensação realizar-se-á sob condição resolutória de sua posterior homologação.

Destarte, conclui-se que o IPI será recolhido ou apurado segundo um sistema de compensação entre créditos e débitos do contribuinte.

\section{Conclusão}

O IPI possui três critérios materiais e, sendo assim, é possível o estabelecimento das seguintes regras matrizes: 
Hipótese Tributária - critério material: importar produto industrializado no exterior; critério espacial: repartições alfandegárias do país; critério temporal: momento do desembaraço aduaneiro. Relação Jurídica Tributária - critério pessoal: o sujeito ativo é a União e o sujeito passivo é o importador; critério quantitativo: a base de cálculo é o valor que servir de base para o cálculo dos respectivos tributos aduaneiros, acrescido do montante desses e dos encargos cambiais devidos pelo importador, sendo que a alíquota é a fixada na tabela.

Hipótese Tributária - critério material: industrializar produtos; critério espacial: em princípio, qualquer lugar do território nacional; critério temporal: o momento da saída do produto do estabelecimento industrial ou equiparado. Relação Jurídica Tributária: critério pessoal: sujeito ativo é a União e sujeito passivo é o titular do estabelecimento industrial ou equiparado ou o responsável tributário; critério quantitativo: a base de cálculo é o preço da operação, na saída do produto, e a alíquota é a percentagem constante da tabela.

Hipótese Tributária - critério material: arrematar produtos apreendidos ou abandonados e levados a leilão; critério espacial: local no qual foi realizado o leilão; critério temporal: o momento da arrematação do produto apreendido ou abandonado. Relação Jurídica Tributária: critério pessoal: sujeito ativo é a União e sujeito passivo é o arrematante de produto apreendido ou abandonado, levado à leilão; critério quantitativo: a base de cálculo é o preço da arrematação em leilão de produtos apreendidos ou abandonados e a alíquota é a percentagem constante da tabela.

Independente de qual seja o critério material do IPI, todos deverão respeitar o princípio da não-cumulatividade previsto no art. 153, §3으, II da Constituição e no art. 49 do CTN

Em relação ao IPI, a Constituição adotou como critério de não-cumulatividade o sistema "imposto sobre imposto", no qual o valor acrescido é definido como sendo a diferença entre o imposto a pagar e o imposto já pago pelos bens adquiridos no mesmo período, portanto, é indiferente o valor acrescido ao produto.

A compensação é o mecanismo que visa garantir maior eficácia ao princípio da nãocumulatividade e pode ser definida como a dedução ou o abatimento dos montantes cobrados de IPI nas operações anteriores. A compensação, no Brasil, é periódica, pois 
trimestralmente abate-se o valor devido por outros contribuintes que the forneceram mercadorias do montante de IPI a pagar.

O princípio da na-cumulatividade e a compensação objetivam evitar o aumento do ônus tributário sobre os produtos finais, pois o IPI é um imposto indireto e, como tal, é repassado para o consumidor (contribuinte de fato) que suporta toda carga tributária sobre os produtos industrializados. Destarte, a compensação é uma técnica que visa proteger o consumidor da incidência "em cascata" deste tributo.

\section{Referências}

BARRETO, Aires. Base de Cálculo, Alíquota e Princípios Constitucionais. 2. ed. São Paulo: Max Limonad, 1998.

BOTTALLO, Eduardo Domingos. Fundamentos do IPI: Imposto sobre Produtos Industrializados. São Paulo: Revista dos Tribunais, 2002.

CARVALHO, Paulo de Barros. Curso de Direito Tributário. 17. ed. São Paulo: Saraiva, 2005.

COSTA, Alcides Jorge. ICM na Constituição e na Lei Complementar. São Paulo: Resenha Tributária, 1978.

ELALI, André de Souza Dantas. IPI: aspectos práticos e teóricos. 1. ed. Curitiba: Juruá, 2005.

MACHADO, Hugo de Brito. Virtudes e defeitos da não-cumulatividade do Tributo no Sistema Tributário Brasileiro. In: MARTINS, Ives Gandra da Silva (Coord.). Direito Tributário e Reforma do Sistema. Pesquisas Tributárias. 9. ed. São Paulo: Revista dos Tribunais \& Centro de Extensão Universitária, 2004.

MARTINS, Ives Gandra da Silva. Questões Atuais de Direito Tributário. Belo Horizonte: Del Rey, 1999. 